\title{
COMPUTER STUDENTS: IDENTIFICATION OF A SUCCESS PROFILE
}

\author{
Sónia Rolland Sobral ${ }^{1}$ \\ ${ }^{1}$ Universidade Portucalense (Portugal)
}

\begin{abstract}
The first cycle courses in Informatics at the Portucalense University have had a curricular evolution, which aligns with the patterns defined by the ACM/IEEE and with the job market's demands. This systematic review of the curriculum has place every two years and, as a practical result, has a high employability rate, which is very near $100 \%$. Like the Informatics course, the Portucalense University has another course, Management of Information Systems, created for students who wish for a more pronounced branch of Management with Informatics. It's recent, but it will surely have employability rates so high as the first one in the future.

However, there is a high percentage of students of the course of Informatics who aren't successful during the course. Especially in the curricular units of the first years, where we can highlight Algorithm and Programming (AP) [1], which is the first curricular unit that the students have in the first semester of the first year and which initiates them in computer programming. Programming Fundamentals (PF) [2] is a curricular unit of the course of Management of Information Systems and appears in the first semester of the second year; the subjects taught in this curricular unit are practically half of those taught in the curricular unit of AP of the Informatics course. PF has less hours, less credits and matches more with a course, which has a combination of management with informatics.
\end{abstract}

These technologically relevant CUs are essential to the appropriate performance of the course, not only for the taught issues, but also because the subjects are chained to the curricular units of the following years. The acquisition of competences for the development of programs in the curricular units is one of the challenges, which the students are required to deal with. The main motive has to do with the need to develop capacity of abstraction, which, as it is known, in Portugal isn't developed with the training in secondary education. In the referred curricular units, the first approach to algorithmic thinking is made, as well as the introduction to programming language to solve small problems. The difficulty in dealing with this problem and the need to search for alternative ways to solve it, with an imperative to know the profile of the students which enter and evolve throughout the semester, the progress of their knowledge through individual and group work.

In this context, this article will present a study based on the students who attended AP, as they attended PF last semester, describe the student's admission profiles, identify some characteristics and habits which may contribute to their developement, as well as attendance to classes and the results achieved. Is it easier do deal with abstraction for the men? Do the students who don't attend the classroom have the same level as the others? On average, how many hours should a student study to be successful? Are fondness, technological dexterity, interest for technology and the motivation referred to above relevant? Does the use of technology favour learning? Is age important? Is the anterior knowledge of some computational techniques better or is it preferable that the students don't have previous programming knowledge? These are some of the questions which the study responds to, aiming to identify the profile of the students with biggest success for the curricular units which initiate university students through the world of programming. 


\section{INTRODUCTION}

The Portucalense University has two courses focused on technologies: information technology and information system management. The first curricular unit of programming, algorithm and programming (AP) appears in the first semester of the first year for computer students. The UC Fundamentals of Programming appears in the 3rd semester (or 1st semester of the 2nd year) for GSI students. While AP has 8 ECTS and a weekly load of 6 hours, FP has 4 ECTS and a weekly face-to-face load of 4 hours. Obviously, the objectives of the unit of PA are much more profound than that of FP, however the first part of the course is common. This common part materializes in three tests at the end of each subprogram:

- Introduction to solving problems, algorithms and tracings. Top-down, Traces, Algorithms. Reading and writing. Variables: manipulation. Types of data. Variable names. Operators and expressions. Mathematical and computational expressions. Conditional control structure: SETHEN-SEP, IF-THEN-ELSE. Divided ifs.

- Language C. Publishers. Compilers.

- Use of cycles: Repetition by counting: DO-FOR; DO-WHILE; Conditional repetition until: REPEAT-UNTIL. Conversion of a REPEAT-UNTIL cycle into a DO-WHILE cycle.

Four surveys were completed by students: one at the beginning of the semester and one at the end of each submatter. Not all students answered the surveys:

In AP of the 49 students initially enrolled, only 23 attended all three tests. This means that, as a result of withdrawal, the percentage of possible success decreases.

In FP of the 7 students initially enrolled, one of them did not take all three tests, and one did not respond to the survey.

\section{INITIAL PORTRAIT OF STUDENTS}

In the first class students were asked to fill out an inquiry whose objective is to take a photograph of the characteristics of the students, as well as to know their habits and expectations. The students' ages were mostly 18 years:

Table 1 . Distribution by age.

\begin{tabular}{|r|r|}
\hline Age & \multicolumn{2}{|l|}{$\%$} \\
\hline 18 & $52,2 \%$ \\
\hline 19 & $8,7 \%$ \\
\hline 20 & $26,1 \%$ \\
\hline 21 & $4,3 \%$ \\
\hline 22 & $8,7 \%$ \\
\hline
\end{tabular}

The students are mostly males, and three students belonged to the computer course (ie, the GSI course was composed only of males). Only $13 \%$ of the total were female.

When asked about their relationship with technology, namely at the level of taste, they are interested in the skill and motivation for learning, ranking from 1 (nothing) to 5 (much), the taste and interest for technology are mainly in the very ; dexterity was classified as level 4 .

Table 2. Relation with technology (1. nothing to 5. much).

\begin{tabular}{|l|c|c|c|c|c|}
\hline & 1 & 2 & 3 & 4 & 5 \\
\hline Technology Geek & $0 \%$ & $0 \%$ & $13 \%$ & $26 \%$ & $61 \%$ \\
\hline Interest in technology? & $0 \%$ & $4 \%$ & $4 \%$ & $30 \%$ & $61 \%$ \\
\hline Technological Dexterity? & $9 \%$ & $0 \%$ & $35 \%$ & $48 \%$ & $9 \%$ \\
\hline Motivation for IT learning & $0 \%$ & $9 \%$ & $4 \%$ & $39 \%$ & $48 \%$ \\
\hline
\end{tabular}


Relatively to the use of technologies, it was verified that all have access to facebook, however a small percentage has account in Linkdin:

Table 3. Use of technologies.

\begin{tabular}{|l|r|r|}
\hline Usa? & Sim & Não \\
\hline Facebook & $100 \%$ & $0 \%$ \\
\hline Gmail & $91 \%$ & $9 \%$ \\
\hline Youtube & $74 \%$ & $26 \%$ \\
\hline Instagram & $52 \%$ & $48 \%$ \\
\hline SnapChat & $52 \%$ & $48 \%$ \\
\hline Twitter & $48 \%$ & $52 \%$ \\
\hline LinkDIn & $9 \%$ & $91 \%$ \\
\hline Google + & $74 \%$ & $26 \%$ \\
\hline Blogs/wordPress & $17 \%$ & $83 \%$ \\
\hline
\end{tabular}

All students use social networking and email.

Table 4. How do you use the Internet?

\begin{tabular}{|l|r|r|}
\hline & \multicolumn{1}{|l|}{ Sim } & \multicolumn{1}{l|}{ Não } \\
\hline $\begin{array}{l}\text { Social } \\
\text { networking }\end{array}$ & $100 \%$ & $0 \%$ \\
\hline Newspapers & $70 \%$ & $30 \%$ \\
\hline $\begin{array}{l}\text { Digital } \\
\text { libraries }\end{array}$ & $43 \%$ & $57 \%$ \\
\hline Games & $74 \%$ & $26 \%$ \\
\hline E-mail & $100 \%$ & $0 \%$ \\
\hline
\end{tabular}

To the question "Had some computer discipline in the secondary" $52 \%$ answered that no and $46 \%$ answered yes. Of the $48 \%$, to the question "If yes: what or which disciplines did you have? In what years? "Everyone answered that they had Computer Applications in the 12th year and one of them said that they had Photoshop in the 6th year and ICT in the 9th year.

To the question "If so: were these disciplines useful? in what form? "We got several types of answers: only one said no; other answers said that "Very Useful, so that you can perceive what is happening inside social networks since most people only use more are not aware of what happens behind it."; "Yes, HTML / Javascript programming bases."; "Yes, you introduced me to the schedule."; "They were useful because they were able to open up my horizons to the world of programming and, in general, motivate me to work in the field of computing"; "Yes, because it allowed for a more solid foundation, or at least have an idea of what would be said at more advanced levels of education." "It was useful to learn how to use word, PowerPoint otherwise."; "I also learned how to use Visual Basic, Movie Maker, Audacity, Gimp, Inkscape and Photoshop."; "It has contributed to the taste for computing and building a basis in programming."

To the question "Do you have prior programming knowledge?": $52 \%$ said yes, while $48 \%$ said no. To those who answered affirmatively, they were asked "which ones? How did you get it? " The answers were: "More or less I do not understand very well, but I have a basic notion of programming."; "HTML / Javascript - 12th Year"; "PHP / WordPress - Alone / Online courses"; "Basic Java through videos on youtube and blog articles"; "Pascal who was taught in the 12th grade"; "I have knowledge in the Pascal language and a short knowledge in C."; "My knowledge in Pascal was acquired through the discipline Computer applications, while my knowledge of $\mathrm{C}$ was through autonomous study."; "Videos on the internet"; "Pascal language, although very basic."; "In the 12th year, in Computer Applications I had to make programs in Visual Basic."; "Pascal, Visual Basic"; "C and C ++."; "Language C", "In another course in another faculty", "Pascal, by Computer Applications". 
Within the students of the course of GSI none had any discipline of programming in the secondary. As for the possession of equipment, we found that all students have a smartphone:

Table 5. possession of equipment.

\begin{tabular}{|c|c|c|c|c|c|c|}
\hline Have & $3 G$ & $4 G$ & $\begin{array}{c}\text { PS4 } \\
\text { (similar) }\end{array}$ & Portatil & Tablet & Smartphone \\
\hline Yes & $83 \%$ & $83 \%$ & $70 \%$ & $96 \%$ & $74 \%$ & $100 \%$ \\
\hline No & $17 \%$ & $17 \%$ & $30 \%$ & $4 \%$ & $26 \%$ & $0 \%$ \\
\hline
\end{tabular}

Regarding the use of use tools, namely the MsOffice package, they stated that regarding MsWord:

Table 6. MsWord knowledge.

\begin{tabular}{|r|r|r|l|r|r|r|}
\hline know & Sections & $\begin{array}{l}\text { Índex } \\
\text { contents }\end{array}$ & $\begin{array}{l}\text { Table } \\
\text { figures }\end{array}$ & Bibliography & Crossrefrence & Header/Footer \\
\hline Yes & $65 \%$ & $87 \%$ & $91 \%$ & $57 \%$ & $13 \%$ & $87 \%$ \\
\hline No & $35 \%$ & $13 \%$ & $9 \%$ & $43 \%$ & $87 \%$ & $13 \%$ \\
\hline
\end{tabular}

Regarding MsExcel

Table 7. MsExcel knowlege.

\begin{tabular}{|r|l|l|l|l|}
\hline \multicolumn{1}{|l|}{ know } & functions & filters & chart & sort \\
\hline Yes & $61 \%$ & $35 \%$ & $65 \%$ & $22 \%$ \\
\hline No & $39 \%$ & $65 \%$ & $35 \%$ & $78 \%$ \\
\hline
\end{tabular}

Regarding MsPowerPoint

Table 8. MsPowerPoint knowlege.

\begin{tabular}{|r|l|l|l|l|}
\hline know & Temporizations & Animations & $\begin{array}{l}\text { Slide } \\
\text { Master }\end{array}$ & Transitions \\
\hline Yes & $78 \%$ & $100 \%$ & $39 \%$ & $91 \%$ \\
\hline No & $22 \%$ & $0 \%$ & $61 \%$ & $9 \%$ \\
\hline
\end{tabular}

As a final question in the first inquiry was asked "In the future I see myself as:" giving 10 options within careers and a response of I do not know anyway. 40\% answered that they did not know how to come in the future. The remaining responses were widely dispersed by the Programmer (a) of applications; Software engineer; Database administrator; Programmer of web sites and multimedia

\section{EVALUATION}

In terms of grades, the results of the three tests are very similar in both courses, as can be seen in the following figure:

Table 9. Average scores for each of the three tests per course.

\begin{tabular}{|l|l|l|l|}
\hline Course & $\begin{array}{l}\text { Average } \\
\text { T1 }\end{array}$ & $\begin{array}{l}\text { Average } \\
\text { T2 }\end{array}$ & $\begin{array}{l}\text { Average } \\
\text { T3 }\end{array}$ \\
\hline GSI & 13,34 & 15,30 & 13,57 \\
\hline Informatics & 10,57 & 14,97 & 12,45 \\
\hline All & 11,3 & 15,4 & 13 \\
\hline
\end{tabular}


If we divide the grades in three: up to 6.66 , from this to 13.33 and up to 20 , we can see that the grades of the GSI students were also slightly better.

Table 10. Range of evaluation of each of the three tests per course.

\begin{tabular}{|l|l|l|l|l|}
\hline Course & Rang & T1 & T2 & T3 \\
\hline \multirow{3}{*}{ GSI } & $1-6.66$ & $0,0 \%$ & $0,0 \%$ & $0,0 \%$ \\
\cline { 2 - 5 } & $6.66-13.33$ & $60,0 \%$ & $40,0 \%$ & $80,0 \%$ \\
\cline { 2 - 5 } & $13.33-20$ & $40,0 \%$ & $60,0 \%$ & $20,0 \%$ \\
\hline \multirow{3}{*}{ Inf } & $1-6.66$ & $5,3 \%$ & $5,3 \%$ & $10,5 \%$ \\
\cline { 2 - 5 } & $6.66-13.33$ & $57,9 \%$ & $26,3 \%$ & $36,8 \%$ \\
\cline { 2 - 5 } & $13.33-20$ & $36,8 \%$ & $68,4 \%$ & $52,6 \%$ \\
\hline
\end{tabular}

Making the equivalent table for sex distribution we found that male students performed better on the first and third test, but female students scored better on the programming language test.

Table 11. Average scores for each of the three tests by sex.

\begin{tabular}{|l|l|l|l|}
\hline Sex & Av T1 & Av T2 & Av T3 \\
\hline $\mathrm{F}$ & 9 & 17,6 & 10,9 \\
\hline $\mathrm{M}$ & 11,7 & 15,1 & 13,3 \\
\hline all & 11,3 & 15,4 & 13 \\
\hline
\end{tabular}

Table 12. Range of Notes for each of the three tests by sex.

\begin{tabular}{|l|l|l|l|l|}
\hline \multirow{2}{*}{ Sex } & Range & T1 & T2 & T3 \\
\hline \multirow{3}{*}{ F } & $1-6.66$ & $33,00 \%$ & $0,00 \%$ & $0,00 \%$ \\
\cline { 2 - 5 } & $6.66-13.33$ & $66,00 \%$ & $33,00 \%$ & $66,00 \%$ \\
\cline { 2 - 5 } & $13.33-20$ & $0,00 \%$ & $66,00 \%$ & $33,00 \%$ \\
\hline \multirow{3}{*}{$\mathrm{M}$} & $1-6.66$ & $10,00 \%$ & $0,00 \%$ & $5,00 \%$ \\
\cline { 2 - 5 } & $6.66-13.33$ & $45,00 \%$ & $35,00 \%$ & $50,00 \%$ \\
\cline { 2 - 5 } & $13.33-20$ & $45,00 \%$ & $65,00 \%$ & $45,00 \%$ \\
\hline
\end{tabular}

Making the equivalent table for distribution by prior programming knowledge, we realized that those who knew programming had a slight advantage.

Table 13. Average of Notes for each of the three tests for previous programming knowledge.

\begin{tabular}{|l|l|l|l|}
\hline Prog Prev? & Av T1 & Av T2 & Av T3 \\
\hline Y & 11,5 & 16 & 17,7 \\
\hline N & 10,9 & 14,8 & 12,2 \\
\hline All & 11,3 & 15,4 & 13 \\
\hline
\end{tabular}

Table 14. Range of Notes for each of the three tests for prior knowledge of programming.

\begin{tabular}{|l|l|l|l|l|}
\hline $\begin{array}{l}\text { Prog } \\
\text { Prev? }\end{array}$ & Range & T1 & T2 & T3 \\
\hline Y & $1-6.66$ & $0 \%$ & $0 \%$ & $0 \%$ \\
\cline { 2 - 5 } & $6.66-13.33$ & $58 \%$ & $25 \%$ & $42 \%$ \\
\cline { 2 - 5 } & $13.33-20$ & $42 \%$ & $75 \%$ & $58 \%$ \\
\hline
\end{tabular}




\begin{tabular}{|l|l|l|l|l|}
$N$ & $1-6.66$ & $18 \%$ & $0 \%$ & $9 \%$ \\
\cline { 2 - 5 } & $6.66-13.33$ & $45 \%$ & $45 \%$ & $55 \%$ \\
\cline { 2 - 5 } & $13.33-20$ & $36 \%$ & $55 \%$ & $36 \%$ \\
\hline
\end{tabular}

Making the equivalent table for distribution by having or not discipline in the secondary, we noticed that there is a slight advantage of the students who had a technological discipline in the secondary.

Table 15. Score average of each of the three tests per secondary discipline.

\begin{tabular}{|l|l|l|l|}
\hline $\begin{array}{l}\text { Disc } \\
\text { Sec? }\end{array}$ & $\begin{array}{l}\text { Average } \\
\text { T1 }\end{array}$ & $\begin{array}{l}\text { Average } \\
\text { T2 }\end{array}$ & $\begin{array}{l}\text { Average } \\
\text { T3 }\end{array}$ \\
\hline $\mathrm{Y}$ & 12 & 15,8 & 13,6 \\
\hline $\mathrm{N}$ & 10,7 & 15,1 & 12,5 \\
\hline Todos & 11,3 & 15,4 & 13 \\
\hline
\end{tabular}

Table 16. Range of Notes for each of the three tests per secondary discipline.

\begin{tabular}{|l|l|l|l|l|}
\hline $\begin{array}{l}\text { Disc } \\
\text { Sec? }\end{array}$ & Range & T1 & T2 & T3 \\
\hline \multirow{3}{*}{ Yes } & $1-6.66$ & $0 \%$ & $0 \%$ & $0 \%$ \\
\cline { 2 - 5 } & $6.66-13.33$ & $55 \%$ & $27 \%$ & $45 \%$ \\
\cline { 2 - 5 } & $13.33-20$ & $45 \%$ & $73 \%$ & $55 \%$ \\
\hline \multirow{2}{*}{ No } & $1-6.66$ & $17 \%$ & $0 \%$ & $8 \%$ \\
\cline { 2 - 5 } & $6.66-13.33$ & $50 \%$ & $42 \%$ & $50 \%$ \\
\cline { 2 - 5 } & $13.33-20$ & $33 \%$ & $58 \%$ & $42 \%$ \\
\hline
\end{tabular}

\subsection{Evaluation number 1}

In the first classes of the unit of AP and of FP the initial concepts were introduced. He began with Introduction to solving problems, algorithms and tracings. Top-down, Algorithms. Reading and writing. Variables: manipulation. Types of data. Variable names. Operators and expressions. Mathematical and computational expressions. Conditional control structure: SE-THEN-SEP, IFTHEN-ELSE. Divided ifs. That is, the passage to computational thinking and the notations of the various instruments. The ranges of notes were

Table 17. 1st Test Report Range.

\begin{tabular}{|l|l|l|l|l|l|l|l|l|l|}
\hline Range & All & GSI & Infor & F & M & Prog & N Prog & Sec & N Sec \\
\hline $1-6.66$ & $13 \%$ & $0,0 \%$ & $5,3 \%$ & $33 \%$ & $10 \%$ & $0 \%$ & $18 \%$ & $0 \%$ & $17 \%$ \\
\hline $6.66-13.33$ & $48 \%$ & $60,0 \%$ & $57,9 \%$ & $66 \%$ & $45 \%$ & $58 \%$ & $45 \%$ & $54 \%$ & $50 \%$ \\
\hline $13.33-20$ & $39 \%$ & $40,0 \%$ & $36,8 \%$ & $0 \%$ & $45 \%$ & $42 \%$ & $36 \%$ & $45 \%$ & $33 \%$ \\
\hline
\end{tabular}

The students were asked to respond to an inquiry about the time between class one and test one. We only got 13 answers from students that we are considering in this article: who have gone to the three tests and answered the first survey (23). Of these 13 students, $30 \%$ considered the test easy, $70 \%$ considered the test with an Average difficulty and none considered difficult.

As for the attendance to the laboratory and theoretical classes, it was asked to self-classify from 1 (never was) to 5 (I went to all). Regarding the theoretical classes, $77 \%$ say that they went to all 
classes and $23 \%$ classify themselves in level $4.70 \%$ of the students said to have gone to all laboratory classes, $23 \%$ to level 4 and $7 \%$ to half of classes.

Regarding the theoretical classes (level 1 to 5): $7 \%$ (3), $70 \%$ (4) and 23\% (5); similar to the laboratory classes.

On average, each student says to study one hour a day out of class.

Regarding the subject matter and considering again a scale of 1 to 5 (nothing to much) we obtain the following table:

Table 18. Auto classification first test subject.

\begin{tabular}{|l|r|r|r|r|r|}
\hline know & 0 & 2 & 3 & 4 & 5 \\
\hline TopDown & $0 \%$ & $8 \%$ & $8 \%$ & $23 \%$ & $62 \%$ \\
\hline Algoritm & $0 \%$ & $8 \%$ & $8 \%$ & $46 \%$ & $38 \%$ \\
\hline Trace & $0 \%$ & $8 \%$ & $0 \%$ & $62 \%$ & $31 \%$ \\
\hline If.then.else & $0 \%$ & $0 \%$ & $8 \%$ & $38 \%$ & $54 \%$ \\
\hline
\end{tabular}

Asking specifically about each of the 6 worksheets or activities proposed, it is concluded that on average the students did $71 \%$ of the work.

In this first phase of work we can not draw great conclusions between men and women, students of GSI and Informatics or students with prior knowledge. We also have the notion that students who did not feel ready for the first test will probably not have appeared and are not included in our article.

\subsection{Evaluation number 2}

In the second phase of Ucs was introduced a programming language. The language chosen was simple C and the editor was Dev C for its ease of use and obviously for being free. Publishers. The ranges of notes were

Table 19. 2nd Test Report Range.

\begin{tabular}{|l|l|l|l|l|l|l|l|l|l|}
\hline Range & All & GSI & Infor & F & M & Prog & N Prog & Sec & N Sec \\
\hline $1-6.66$ & $0 \%$ & $0,00 \%$ & $5,30 \%$ & $0,00 \%$ & $0,00 \%$ & $0 \%$ & $0 \%$ & $0 \%$ & $0 \%$ \\
\hline $6.66-13.33$ & $65 \%$ & $40,00 \%$ & $26,30 \%$ & $33,00 \%$ & $35,00 \%$ & $25 \%$ & $45 \%$ & $27 \%$ & $42 \%$ \\
\hline $13.33-20$ & $35 \%$ & $60,00 \%$ & $68,40 \%$ & $66,00 \%$ & $65,00 \%$ & $75 \%$ & $55 \%$ & $73 \%$ & $58 \%$ \\
\hline
\end{tabular}

The students were asked to respond to an inquiry about the time they spent between test number one and test number two. We only get 16 responses from students we are considering in this article. Of these 16 students, 6 considered the test easy, 9 considered the test with an average difficulty and one considered difficult.

As for the attendance to the laboratory and theoretical classes, it was asked to self-classify from 1 (never was) to 5 (I went to all). Regarding the theoretical classes, $63 \%$ said that they went to all 
classes and $37 \%$ classified in level $4.44 \%$ of the students said to have gone to all laboratory classes, $44 \%$ level 4 and $12 \%$ to half the classes.

Regarding the theoretical classes (level 1 to 5): $31 \%$ (3), $25 \%$ (4) and $43 \%$ (5); similar to the laboratory classes.

On average each student says they study five hours a week outside of class.

Regarding the subject matter and considering again a scale of 1 to 5 (nothing to much) we obtain the following table:

Table 20. Self-classification second test subject.

\begin{tabular}{|l|r|r|r|r|r|}
\hline Know & 0 & 2 & 3 & 4 & 5 \\
\hline $\begin{array}{l}\text { New } \\
\text { program }\end{array}$ & $0 \%$ & $6 \%$ & $0 \%$ & $56 \%$ & $38 \%$ \\
\hline $\begin{array}{l}\text { Declare } \\
\text { vars C }\end{array}$ & $0 \%$ & $6 \%$ & $6 \%$ & $19 \%$ & $69 \%$ \\
\hline $\begin{array}{l}\text { Use } \\
\text { functions }\end{array}$ & $0 \%$ & $6 \%$ & $18 \%$ & $18 \%$ & $56 \%$ \\
\hline If.then.else & $0 \%$ & $0 \%$ & $0 \%$ & $38 \%$ & $62 \%$ \\
\hline
\end{tabular}

Asking specifically about each of the 6 worksheets or proposed activities, it is concluded that $75 \%$ of the students have done all the work proposed.

In this first phase of work we can not draw great conclusions between men and women, students of GSI and Informatics or students with prior knowledge.

\subsection{Evaluation number 3}

Between the second and third test of AP and FP the subject was Use of cycles: Repetition by counting: DO-FOR; DO-WHILE; Conditional repetition until: REPEAT-UNTIL. Conversion of a REPEAT-UNTIL cycle into a DO-WHILE cycle. We used algorithm writing tools as well as coding programs in $\mathrm{C}$.

Table 21. 3rd Test Report Range..

\begin{tabular}{|l|l|l|l|l|l|l|l|l|l|}
\hline Range & all & GSI & Infor & F & M & Prog & N Prog & Sec & N Sec \\
\hline $1-6.66$ & $4 \%$ & $0,00 \%$ & $10,50 \%$ & $0,00 \%$ & $5,00 \%$ & $0 \%$ & $9 \%$ & $0 \%$ & $8 \%$ \\
\hline $6.66-13.33$ & $52^{\wedge} \%$ & $80,00 \%$ & $36,80 \%$ & $66,00 \%$ & $50,00 \%$ & $42 \%$ & $55 \%$ & $45 \%$ & $50 \%$ \\
\hline $13.33-20$ & $43 \%$ & $20,00 \%$ & $52,60 \%$ & $33,00 \%$ & $45,00 \%$ & $58 \%$ & $36 \%$ & $55 \%$ & $42 \%$ \\
\hline
\end{tabular}

The students were asked to respond to an inquiry about the time between test two and test three. We only got 17 answers. Of these 17 students, none considered the test easy, $82 \%$ considered the test with an average difficulty and $18 \%$ considered difficult.

As for the attendance to the laboratory and theoretical classes, it was asked to self-classify from 1 (never was) to 5 (I went to all). Regarding the theoretical classes, $64 \%$ say that it was all classes and $12 \%$ is classified in level 4 and $24 \%$ level 3 . The values are very similar to those of the laboratory classes.

On average each aulo says to study six hours a week outside of class.

Regarding the subject matter and considering again a scale of 1 to 5 (nothing to much) we obtain the following table: 
Table 22. Self-classification 3rd test subject

\begin{tabular}{|l|r|r|r|r|r|}
\hline know & 0 & 2 & 3 & 4 & 5 \\
\hline C Program & $0 \%$ & $0 \%$ & $29 \%$ & $41 \%$ & $24 \%$ \\
\hline For & $0 \%$ & $6 \%$ & $24 \%$ & $53 \%$ & $18 \%$ \\
\hline While & $0 \%$ & $0 \%$ & $41 \%$ & $41 \%$ & $18 \%$ \\
\hline
\end{tabular}

Asking specifically about each of the 6 worksheets or activities proposed, it is concluded that on average the students did $24 \%$ of the work.

\section{CONCLUSIONS}

In this article, we try to draw a success profile for the curricular units of introduction to the studied programming: Algorithm and Programming and Fundamentals of Programming, respectively of the course of computer science and management of information systems. The study was only done for an initial part of both UCs. In the first test will be a man, from the course of gsi, who has prior knowledge of programming and who had a technological discipline in secondary education. In the 2nd test will be a woman, from the computer course, who has previous programming knowledge and who had a technological discipline in secondary education. In the 3rd test will be a man, from the computer course, who has prior knowledge of programming and who had a technological discipline in secondary education.

We have again verified that many students disappear from classes and assessment from the moment the programming language is introduced.

In the future, it will be important to gauge the number of hours that the students study outside the class, if they are attending classes and if they do all the proposed work or only some.

\section{REFERENCES}

[1] UPT, "Algoritmia, Ficha da Unidade Curricular 2017/2018," 01 Set 2017. [Online]. Available: https://siupt.upt.pt/aulas/ficha_uc_impressao.php?df_id=3245. [Accessed 01 Mar 2018].

[2] UPT, "Fundamentos, Ficha da Unidade Curricular 2017/2018," 01 Set 2018. [Online]. Available: https://elearn1718.uportu.pt/mod/url/view.php?id=3452. [Accessed 01 Mar 2018]. 